\title{
Relationship between Oxidation of Metal Surface Layer and Air Quality in Wuhan
}

\author{
Mengmeng Hou ${ }^{1, *}$ and West Gabllian ${ }^{2}$ \\ ${ }^{1}$ School of Management, Wuhan University of Technology, Wuhan, China, 430074 \\ ${ }^{2}$ School of Engineering, University of Florida, Gainesville, FL, US \\ * Corresponding author: 2426935187@qq.com
}

\begin{abstract}
In order to find out the relationship of steel futures price with different manganese content, a local fractional algorithm is proposed in this paper. We use three analytical tools - price discovery analysis, arbitrage analysis and a case study approach to assess the magnitude of price divergence risk and determine the hedging effectiveness of steel billet futures. The results show that the proposed method can thus improve overall system performance substantially.
\end{abstract}

\section{Introduction}

Steel is one of the most important alloys in the world. It is used to make a variety of products that are used in agriculture, construction, healthcare, industry and transportation. There are two types of steel products - flat products and long products. Flat products include plates, hot-rolled strips and sheets, and cold-rolled strips and sheets. These products are used in automotive, heavy machinery, pipes, and tubes, construction, packaging, and appliances. Long products include billets, blooms, re-bars, wire rods, rails and drawn wire. Long products are used in construction, mechanical engineering, and energy industries. Steel products are generally produced from iron ore or steel scrap - recycled steel. Global steel production has increased by leaps and bounds in the last few decades, from 568 million tons in 1980 to 1548 million tons in 20122. Few decades back, major steel producers were located in First World countries in North America and Europe. However, in the last 20 years, the focus of steel production has shifted to developing countries such as China, India, Brazil and Turkey. Today, steel has emerged as one of the most widely traded commodities in the world, with several countries active in the steel trade, either as net steel importer or exporter. The global steel industry has historically been a highly cyclical industry. It is strongly linked to expectations of future economic conditions. As a result, steel prices are generally very volatile. High price volatility affects the economic decisions of steel manufacturers, merchants and users in several industries, particularly in automotive and construction industries. Unlike other metals and alloys such as copper, lead and gold, steel is a highly differentiated product. There are several varieties of steel that fall under the flat and long products categories [1-2]. These varieties differ in chemical composition, dimensions and other parameters. Due to such high variety of steel products, managing steel price risk is a difficult proposition, as each variety has a different market and thus pricing benchmark. But given the sheer size of the industry and the importance of the alloy for business, it was inevitable that a hedging tool be developed to effectively manage steel price risk. Hence, in the last decade, the steel industry witnessed the introduction of several futures contract, to assist the process of steel price risk management. Amidst all the contracts, the one that gained most traction amongst steel users was the steel billet futures contract launched by the London Metal Exchange.

\section{LME Steel Billet Futures Contract}

The London Metal Exchange (LME) is the leading global exchange for trading of metals and alloys. In 2008, the LME introduced futures contract for steel billet that could be delivered in two regions - the Mediterranean and the Far East. Steel billet is a semi-finished steel product that is used for making other long steel products such as bars, rods and pipes. In 2010, the two contracts were merged into a single contract. The specifications of the contract are provided in Appendix A. The contract served the following purposes [3]:

Hedge price volatility: The primary objective of the steel billet futures was to help producers, users and merchants in hedging price volatility of steel products. Market of last resort: The users of the contract could use the London Metal Exchange as a market of last resort, and thus sell or buy steel billet whenever it was not possible for them to do so in the physical steel billet market. Benchmark pricing: As mentioned earlier, steel is a highly differentiated product, with each 
variety having its own unique market and pricing mechanism. Hence, it is difficult to obtain a benchmark steel price, given the high variety. The futures price would serve as a benchmark for all components in the steel supply chain. For example, scrap traders, who deliver scrap for production of steel billet, as well as wire rod manufacturers could use steel billet futures prices to price their products [4].

Long term fixed sales price: The steel billet futures was also introduced to enable manufacturers to offer long term fixed sales price for their steel products and thus lock in profit margins. Initially the steel billet futures contract was divided into the Mediterranean and Far East contracts. Volumes in the first few years were not significantly high, as steel users were skeptical of the hedging and benchmarking function of the futures contract [5]. Thus, volumes in the first two years of the contract were not high. However, since the Mediterranean and Far East contracts were merged into a single steel billet futures contract in 2010, traded volumes increased, reflecting the growing popularity of the LME steel billet futures contract. During this period, the number of participants in the steel billet futures market increased significantly and major banks such as the Deutsche Bank used the contract significantly. However, in the last couple of years traded volume has decreased significantly. The declining trend in traded volumes is shown in the Figure 1 . The data for Figure 1 excluded traded volume on July 31st, 2012 where the number of contracts traded was 660 . This observation was in stark contrast to the significantly lower volumes observed on days before and after this date. Thus, to show the clear declining trend, this observation has been excluded in Figure 1.

Tracking physical steel billet markets: The price of the futures contract of any commodity should be closely interlinked with the price of the physical commodity in different regions. If the futures and physical market prices diverge, then it implies inefficiency in pricing of the commodity in either market. In Figure 2, the price of LME 3month steel billet futures has been shown against the price of Black Sea Export FOB billet and East Asia Import Billet CFR.

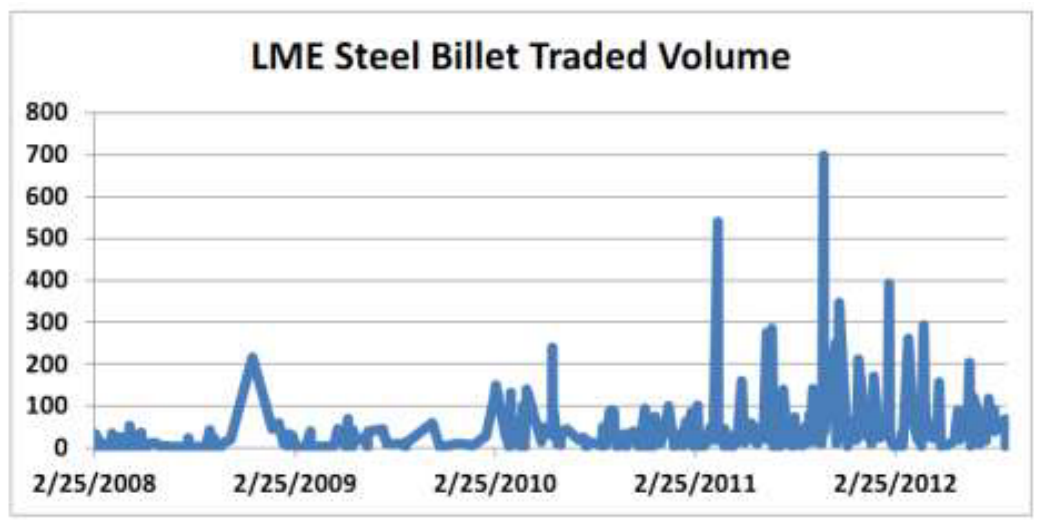

Fig. 1. The traded volume of the LME steel billet futures contract

These two billet benchmark prices are important as the Black Sea and East Asia regions are the largest trading hubs of steel billet in the world. Please note that the terms FOB and CFR, along with export and import billet are not important in our discussion. There is difference in the absolute values of all three prices, due to the difference in steel billet prices in different regions. We notice that the gap between the LME steel billet price graph and the other two billet prices graphs is insignificant in the first few years of the futures contract. This indicates that the steel billet futures price was an excellent benchmark of global steel billet, since most of the steel billet trade is centered in the Black Sea and East Asia regions. However, the gap increases in the last two years of the contract. This indicates that in the last two years, the steel billet futures price has not closely tracked the price of steel billet in major physical markets. Thus, the benchmarking ability of steel futures contracts has declined in the last two years.

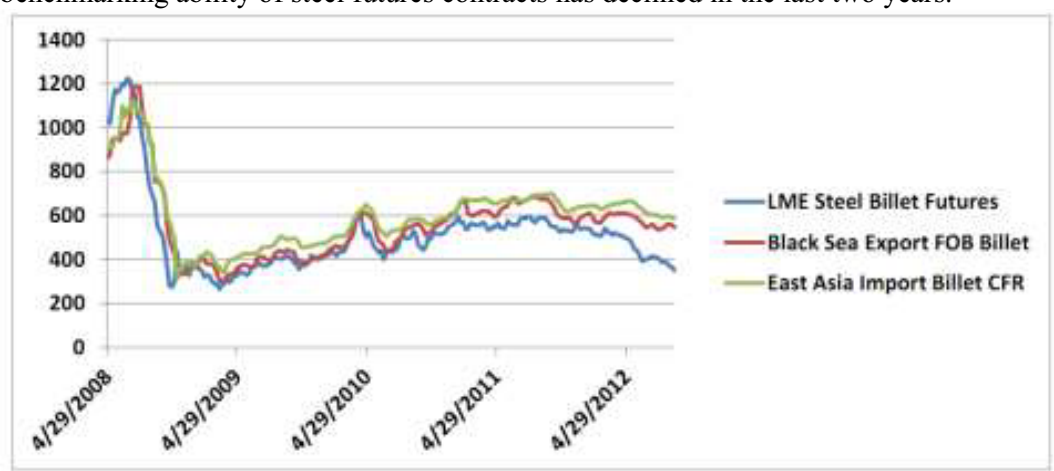

Fig. 2. The prices of the LME steel billet futures against the prices of spot billet in important physical markets in East Asia and the Black Sea region. 


\section{The Algorithm}

The price discovery analysis entails analysis of the price discovery process in the futures market and the correlation between price changes in the futures and cash markets. The analysis of price discovery will help us determine which of the two markets is dominant over the other in terms of flow of information. Perfect and complete flow of information between the two markets ensures that prices in both markets always move in synchronization. Analysis of price discovery also presents us with information of elasticity of supply of arbitrage services, a measure that will be defined in the next section. The elasticity of supply of arbitrage services, along with price discovery analysis helps make inferences about the price divergence risk in using the futures contract for hedging. The local fractional algorithm can be expressed as following:

$$
\begin{aligned}
f^{(\alpha)}(x 0) & =\left.\frac{d f(x)}{d x^{\alpha}}\right|_{x=x_{0}} \\
& =\lim _{\delta x \rightarrow 0} \frac{\Delta^{\alpha}\left(f(x)-f\left(x_{0}\right)\right)}{\left(x-x_{0}\right)^{\alpha}}
\end{aligned}
$$

for $0<a \leq 1$ where

$$
\begin{aligned}
& \Delta^{\alpha}\left(f(x)-f\left(x_{0}\right)\right) \cong \\
& \Gamma(1+\alpha) \lim _{x \rightarrow \infty} \Delta\left(f(x)-f\left(x_{0}\right)\right)
\end{aligned}
$$

And local fractional integral of $f(x)$ defined by Eq.3.

$$
\begin{aligned}
& { }_{a} I_{b}^{(\alpha)} f(t)=\frac{1}{\Gamma(1+\alpha)} \int_{a}^{b} f(t)(d t)^{\alpha} \\
& =\frac{1}{\Gamma(1+\alpha)} \lim _{\Delta t \rightarrow 0} \sum_{j=0}^{j=N-1} f\left(t_{\mathrm{j}}\right)\left(\Delta t_{\mathrm{j}}\right)^{\alpha}
\end{aligned}
$$

With $\Delta t_{j}=t_{j+1}-t_{j}$ and $\Delta t=\max \left\{\Delta t_{1}, \Delta t_{2}, \cdots, \Delta t_{j}, \cdots\right\}$, where for $j=1,2, \cdots, N-1,\left[t_{j}, t_{j+1}\right]$ is a partition of the interval $[a, b]$ and $t_{0}=a, t_{N}=b$.

If $f(x)$ is defined on the real line $-\infty<x<\infty$, its local fractional Hilbert transform, denoted by $f_{x}^{H, \alpha}(x)$ is defined by

$$
\begin{aligned}
& H_{\alpha}\{f(t)\}=\hat{f}_{H}^{\alpha}(x) \\
& =\frac{1}{\Gamma(1+\alpha)} \int_{R} \frac{f(t)}{(t-x)^{\alpha}}(d t)^{\alpha}
\end{aligned}
$$

Where $x$ is real and the integral is treated as a Canchy principal value, that is,

$$
\begin{aligned}
& \frac{1}{\Gamma(1+\alpha)} f_{R} \frac{f(t)}{(t-x)^{\alpha}}(d t)^{\alpha} \\
& =\lim _{\varepsilon \rightarrow 0}\left[\frac{1}{\Gamma(1+\alpha)} \int_{-\infty}^{x-\varepsilon} \frac{f(t)}{(t-x)^{\alpha}}(d t)^{\alpha}+\right. \\
& \left.\frac{1}{\Gamma(1+\alpha)} \int_{x+\varepsilon}^{\infty} \frac{f(t)}{(t-x)^{\alpha}}(d t)^{\alpha}\right]
\end{aligned}
$$

To obtain the inverse local fractional Hilbert transform, write again Eq. (4) as

$$
\begin{aligned}
& \hat{f}_{H}^{\alpha}(x)=\frac{1}{\Gamma(1+\alpha)} \int_{-\infty}^{\infty} \frac{f(t)}{(t-x)^{\alpha}}(d t)^{\alpha} \\
& =\frac{1}{\Gamma(1+\alpha)} \int_{-\infty}^{\infty} f(t) g(x-t)(d t)^{\alpha} \\
& =f(x) * g(x),
\end{aligned}
$$


The elasticity of supply of arbitrage services is a measure of the rate of convergence of cash and futures prices. Garbade and Silber postulate that if elasticity of supply of arbitrage services is zero then the futures market is a poor substitute for the cash market position. Prices in both markets follow uncoupled random walks and the futures markets' risk transfer and price discovery functions are eliminated. The futures contract is thus an ineffective hedging tool for the hedger as price divergence risk is high. On the other hand, if elasticity of arbitrage services is infinite, then futures contract is a perfect substitute for the cash market position. In this case, prices are discovered simultaneously in both markets and the futures contract serves as a perfect hedging tool since price divergence risk is low. For non-zero and non-infinite values of elasticity, the two markets follow an intertwined random walk, with one market dominant over the other in terms of price determination. In this case, the futures contract can be used to hedge but the hedge will not be perfect due to price divergence risk.

\section{References}

1. Benrun Huang, Li Xia, Zhengguo Wu, Weiping Zhou. Control Strategy of A Dynamic Voltage Restorer (DVR) Based on Line Voltage Compensation. Energy Procedia, (2011), pp. 13-26.

2. Wei Dai, Mostafa Bassiouni. An improved task assignment scheme for Hadoop running in the clouds. Journal of Cloud Computing, (2013), pp. 21-33.

3. Wei Kuang Lai, Yi-Uan Chen, Tin-Yu Wu, Mohammad S. Obaidat. Towards a framework for large-scale multimedia data storage and processing on Hadoop platform. The Journal of Supercomputing, (2014), pp. 681-696.

4. Zhijian Chen, Wenhai Luo, Dan Wu, Xiang Huang, Jian He, Yuanhuan Zheng, Di Wu. Exploiting application-level similarity to improve SSD cache performance in Hadoop. The Journal of Supercomputing, (2014), pp. 703-715.

5. Y. Mishing, in: Diffusion Processes in Advanced Technological Materials, edtied by D. Gupta Noyes Publications/William Andrew Publising, Norwich, NY (2004), in press. 